\title{
Fused Silica.
}

\section{By Sir Richard Pager, Bart.}

'T OUGH silica $\left(\mathrm{SiO}_{2}\right)$, either free or combined, is the commonest constituent of the earth's crust, and is estimated to constitute sixty per cent. of the first ten miles depth, there are no sources of silica sufficiently pure for fusion known in Great Britain. 'The highest grades of transparent fused silica "glass" are made from rock crystal, or from deposits of minute crystals, commercially known as geyserite, which occur in Germany, Sweden, and elsewhere. True geyserite, however, is a semi-hydrated silica of the opal type, deposited by water containing dissolved $\mathrm{SiO}_{2}$. The celebrated pink and blue terraces in New Zealand, which were destroyed by the volcanic eruption of Mount Tarawera in $x 886$, consisted of silica in the form of geyserite. Pure silica occurs also rarely in other crystalline forms known as tridymite and crystobalite. Opaque fused silica ware is made by the fusion of pure silica sand, of a silica content of about ninety-nine per cent.

Silica fused by lightning has been found in many countries, particularly in the form of long tubes, $\frac{1}{4}$ in. to $\frac{1}{2}$ in. in diameter, produced by the passage of the electric discharge through a bed of silica sand. These are known as fulgurites or Le Chatelierite, and were first observed in I7II by Hermann in Silesia, and attributed to lightning by Dr. Hentzen, in Westphalia, in 1805. Darwin, in the "Voyage of H.M.S. Beagle," refers to the Uruguayan fulgurites. A specimen $37 \mathrm{ft}$. in length has been found in Drigg, Cumberland.

The earliest experiments in silica fusion were made in 1838 by Gaudin, of Paris, who fused rock crystal by means of the oxy-hydrogen blowpipe. He found that fused quartz never became truly fluid ; that it began to volatilise near its melting point; that on cooling it formed a transparent glassy mass, which was unaffected by sudden changes of temperature, and showed remarkable strength and elasticity; and that on prolonged heating the glassy mass returned to a crystalline condition and lost its mechanical strength. In 1878 Gautier exhibited small fused quartz tubes made in a blowpipe.

In I888, Sir Charles Parsons made extended experiments in heating carbon and other substances to a very high temperature under pressures of from 5 to 30 tons per sq. inch, and in this connexion he fused small quantities of silica sand by means of an electrically heated carbon rod surrounded by the sand. In $x 887$, Vernon Boys devised his method of drawing fine quartz threads by attaching one end of an anchored quartz rod to the arrow of a miniature crossbow, heating the rod with a blowpipe, and discharging the arrow so that its flight drew out a thread. This process was, in a sense, the forerunner of the present methods by which fused silica rods and tubes are now drawn out, but on a larger scale, with this difference, that the initial fusion is made by means of an electric resistance heating, and that the drawing-out process is performed in a slower and less poetic fashion than by the flight of an arrow.

About r889, Vernon Boys, at Leeds, made fused quartz tubes by fusing pieces of rock crystal in the blowpipe, drawing them out into rods and winding these rods into the form of a closed helix, of which the adjacent coils were then fused together in a blowpipe so as to form a continuous tube. In I899, Threlfall, at Oldbury; fused quartz in quantity in a $100 \mathrm{kw}$. arc furnace.

The earliest fused quartz lens was exhibited by Schott and Genossen at the Paris Exhibition of 1900 ; and in the following year Shenstone demonstrated his method of building up fused silica tubes by fusing together a number of rods assembled faggot-wise around a platinum core. In 1903 , Heræus greatly improved the technique by fusing rock crystal inside an iridium tube and afterwards working the product in the blowpipe. In Great Britain, Johnson and Matthey took up the work of Shenstone, and developed Kent's method of building up bubble-free fusions by feeding a rock crystal powder into the heated zone of an electric arc.

Numerous attempts have been made to avoid the formation of bubbles in the fusing of silica, for, as Gaudin originally showed, the material never becomes liquid, so that bubbles cannot float to the surface. Day and Shepherd in the United States showed that the liquid condition is not reached even when silica is superheated at a pressure of 35 atmospheres. In 1904 and I 905 , Bredel, in Germany, proposed a method of fusing in vacuo, and, in particular, of fusing the mass from below, so as to avoid the inclusion of bubbles. In the United States, in I906, Wingrens patented a process of silica fusion in vacuo, and in the same year Day and Shepherd produced transparent silica plates by fusion at $2000^{\circ} \mathrm{C}$., followed by a further heating at $1800^{\circ} \mathrm{C}$. under a gaseous pressure of $500 \mathrm{lb}$. In I907, Ludwig Bolle in Germany patented a process of silica fusion in a tubular furnace, the fusion being extruded by mechanical or gaseous pressure.

Reverting now to the fusion of silica sand, Elihu Thomson, in America, R. S. Hutton, at Owens College, Manchester, and Ruhstradt, in Germany, developed a process similar to that of Sir Charles Parsons, but working at atmospheric pressures. Hutton also made small fused silica tubes by enclosing a layer of silica in a graphite trough, a graphite core being supported axially within the trough, and heating the fusion from above by means of a travelling electric arc. At Oldbury, Threlfall, using the same method as Hutton, Elihu Thomson, and Ruhstradt, made rough tubes up to 5 in. and 6 in. in diameter (in one case up to 12 to $x_{5} \mathrm{ft}$. in length). In all these processes it was essential to keep the temperature as low as possible, so as to avoid the reaction which takes place at high temperatures between silica and carbon, producing carborundum and evolving carbon monoxide.

In 1903 experiments were started at Wallsend under the late Dr. J. F. Bottomley, with R. S. Hutton as consultant, with the object of developing a commercial method of silica fusion by means of electric resistance or arc heating. After many months of failure, the first success was obtained in I904. A mass of silica fused round a central heating core became overheated, and the evolution of carbon monoxide gas caused the plastic

$$
\text { NO. } 2847 \text {, VOL. I I } 3]
$$


(a)
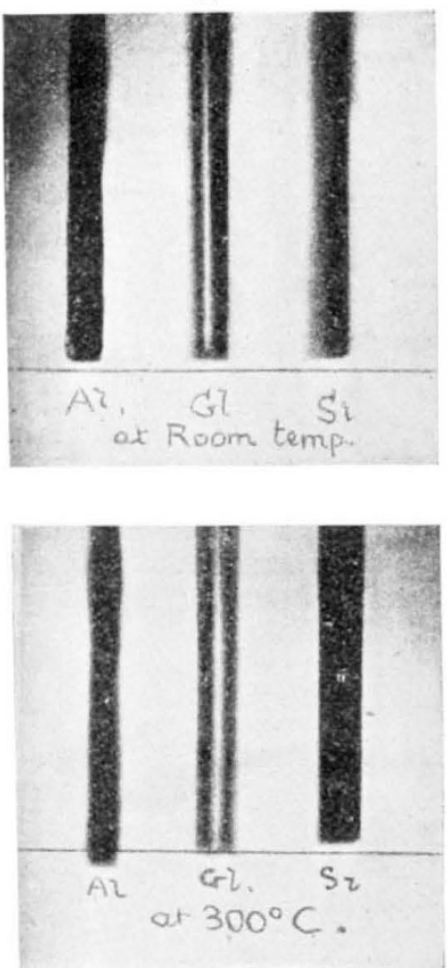

(c) (b)
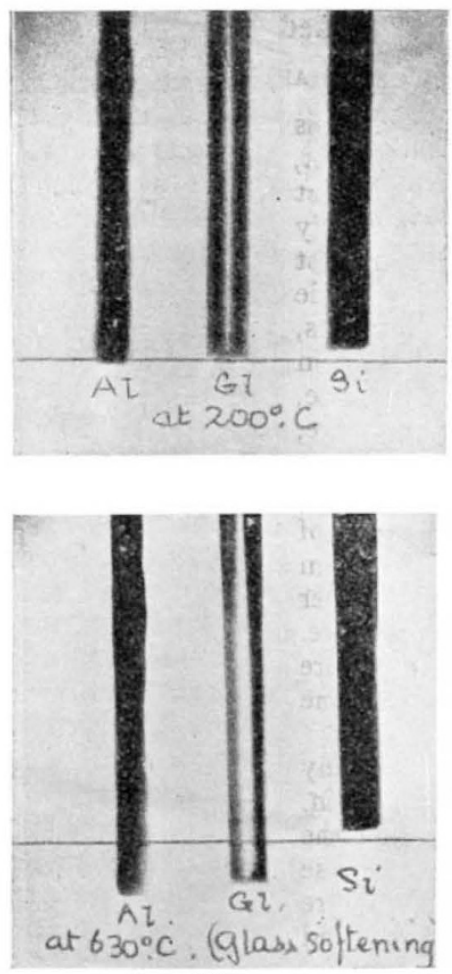

(d)
FiG. 1.-The effect of heating rods of fused silica, aluminium, and glass.

the fused mass between water-cooled dies. This Company has also produced opaquemoulded insulators for high-tension work by Elihu Thomson's method.

The most important property of fused silica is its low coefficient of expansion. In this respect fused silica stands in a class by itself, its expansion being less than one-sixth of that of the best Jena or Pyrex glasses, and less than one-twentieth of the high-expansion glasses. The relative expansion of rods of fused silica, glass and a metal, such as aluminium or copper, may be shown by suspending rods of similar length inside a tubular furnace, and throwing the shadow of the projecting ends of the rods on to the screen. Fig. I shows (with suitable magnification) the result of heating rods of fused silica, aluminium, and glass, each of about $30 \mathrm{~cm}$. length when at room temperature, to temperatures of $200^{\circ}, 300^{\circ}$, and $630^{\circ} \mathrm{C}$.

The practical effect of the low coefficient of expansion of fused silica may be demonstrated by heating rods of fused silica, Jena, Pyrex, and other glasses, afterwards dipping them into cold water. Under this treatment a mass of cracks develops throughout the chilled portion of the glasses, but the fused silica is quite unaffected. Fig. 2 shows the result of quenching rods of Jena, Pyrex, and

fusion to be blown up into the form of a large " ostrich egg." From this accidental result was developed the present methods whereby fused silica is melted by means of an electrically heated carbon or graphite rod. When the fusion has been brought to the right degree of plasticity the rod is withdrawn, and the fusion is drawn, or blown by internal gas pressure, either freely or into a mould, or is pressed or rolled without reheating.

The essential conditions are that the fusion shall not touch the rod, excepting at its relatively cool extremities. This is effected by so adjusting the temperature that there is an initial evolution of gas and silica vapour which inflates the fusion just sufficiently to keep it clear of the rod, while not allowing the fusion to become so plastic as to flow down on to the rod. This process was commercially developed by the Thermal Syndicate Ltd., which sold its products under the trade name "Vitreosil." 1 The change from crystalline quartz to the amorphous condition is stated to begin at $x 400^{\circ} \mathrm{C}$., melting at $1650^{\circ} \mathrm{C}$., and the plastic condition at between $1750^{\circ} \mathrm{C}$. and $1800^{\circ} \mathrm{C}$.

Between 1907 and I9ro, Dr. Volker, in Germany, developed an alternative to the Thermal Syndicate process, in which the fusion was blown up, after the withdrawal of the heating core, by introducing a slice of potato or other moisture-containing substance inside the fusion before closing it at either end by mechanical pressure.

In America the General Electric Co. has, in recent years, produced transparent rods and tubes by fusing rock crystal in vacuo in a tubular furnace, and drawing

1 See Patents No. $10670 / 04$, Bottomley, Hutton, and Paget; No. 18437 'o4 Bottomley and Paget; No. 9522/05, Bottomley and Paget ; No. 14774/06, Bottomley and Paget.

NO. 2847 , VOL. I I 3$]$ fused silica glass when heated to $540^{\circ} \mathrm{C}$.

The relatively high softening point may be shown by clamping a number of similar silica and glass rods at one

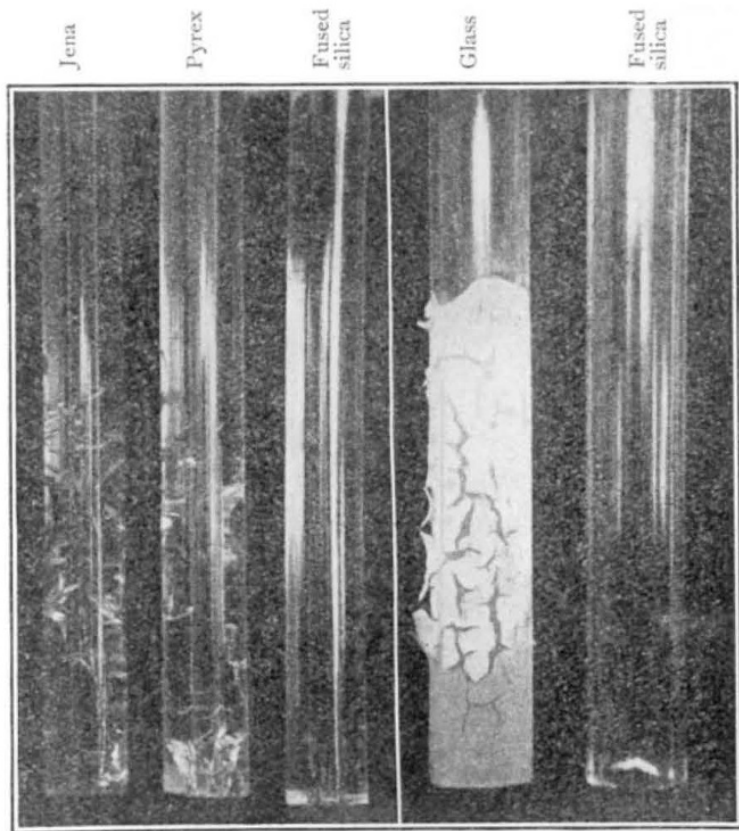

FIG. 2.-Rods of Jena, Pyrex, and FIG. 3.-Rods of German glass fused silica glass quenched from tubing (potash glass as used com$540^{\circ} \mathrm{C}$. $\quad$ monly in laboratories) and fused silica after $1 \frac{1}{2}$ min. immersion in strong hydrofluoric acid, washing and dying. The glass rod is silica liberated by the treatment. 
end, projecting horizontally over a number of bunsen burners, the burners being fixed on to a common base, so that they can be all applied simultaneously to their respective rods. Under this treatment the most refractory glasses readily bend under their own weight, whereas the fused silica rod is quite unaffected.

The low coefficient of expansion of fused silica has found an interesting application in the case of the National Physical Laboratory standard metre bars, which consist of a fused silica tube having a projecting tongue or "tenon" in the form of strips of optically worked fused silica let in longitudinally across each end of the rod. The actual measurements are taken from fine engraved lines formed on the surface of the projecting tenons. The properties of low coefficient of expansion and high softening point find practical use in such apparatus as muffles, retorts, pyrometer tubes, roasting trays, and combustion tubes.

As Gaudin pointed out, vitreous silica tends, on prolonged heating, to return to the crystalline form. This change is accompanied by a reduction in volume of from 3 to 5 per cent., and the crystalline mass consists of small crystals of crystobalite, or of tridymite, or both, according to the temperature, times, and other conditions of heating. Devitrification scarcely commences at $\mathrm{I} 22^{\circ} \mathrm{C}$, but is appreciable after four hours of continuous heating at $1140^{\circ} \mathrm{C}$. Above this temperature continuous heating gradually converts vitreous silica into crystobalite.

Silica heated in the presence of a suitable catalyst, such as chloride of potassium or lithium, devitrifies at considerably lower temperatures; thus, continuous heating for eight days at $800^{\circ} \mathrm{C}$. converts vitreous silica into tridymite.

The physical properties of fused silica have been fully dealt with by Prof. Georges Flusin, of Grenoble, in Chimie et Industrie, of June I920. Pure fused silica devitrifies less rapidly than silica mixed with any known substances. The density of transparent fused silica is $2 \cdot 2 \mathrm{I}$, while that of the opaque variety is 2.07 ; the difference is due to the inclusion of minute bubbles in the opaque mass. The hardness of fused silica is of the same order as that of hard glass. Its elasticity is rather higher than Jena glass, namely, $6 \cdot 6 \mathrm{~kg}$. per mm. ${ }^{2}$ as against 6.0 for Jena glass. The crushing strength is about 7 tons per sq. in., i.e. between that of granite and blue brick. The tensile strength of quartz fibre, provided the surface is unscratched, is 70 tons per sq. in. Its shear rigidity modulus is $3.0 \times 10^{\mathbf{1 1}}$ dynes per $\mathrm{cm} .^{2}$, as compared with copper $4.0 \times 10^{11}$, crown glass $2 \cdot 9 \times 10^{11}$, flint glass $2 \cdot 3 \times 10^{11}$.

Fused silica becomes more resistant to shear with increasing temperature up to $1000^{\circ} \mathrm{C}$., its rigidity at $80^{\circ}$ being about 7 per cent. higher than at room temperature. Heavy articles of fused silica which have been allowed to cool rapidly are increased in strength by reheating for four hours at $x \mathrm{r} 88^{\circ}$, due to the removal of strains produced during cooling. The heat conductivity of fused silica is of the same order as that of glass.

The most interesting chemical property of fused silica is its resistance to acids. Fused silica is completely insoluble in all acids or mixtures of acids, except hydrofluoric (in which its solubility is less than onetenth of that of common glasses) and hot concentrated phosphoric acid, in which it begins to dissolve appreciably at $300^{\circ} \mathrm{C}$. Fig. 3 shows a rod of fused silica and a rod of German glass, after immersion for $I \frac{1}{2}$ minutes in strong hydrofluoric acid, washing and drying; the opaque surface of the glass rod is due to liberation of gelatinous silica. Figs. 4 and 5 show a collection of exhibits of fused silica ware for chemical purposes, etc.

The International Atomic Weight Commission has recommended the use of silica vessels for analytical operations of high precision. Fused silica is entirely insoluble in water, which is not the case with the glasses. It is, therefore, of material use in refined chemical work where contamination by minute traces of alkali, due to the solvent action of the reagent, has to be avoided.

Fused silica begins to volatilise appreciably below its melting point, and this fact must be borne in mind in analytical work involving temperatures above $135^{\circ} \mathrm{C}$. It is completely resistant to steam, and has been successfully used for gauge glasses for steam boilers.

Solutions of neutral salts may be evaporated to dryness and the resulting salts fused in silica vessels, usually without any chemical reaction occurring with the fused silica. Alkaline solutions and basic salts, however, attack fused silica to an extent depending upon the nature of the substance, and upon the conditions of concentration and temperature. Prolonged ignition of a silica vessel contaminated with traces of mineral salts produces a crumbling of the surface of the vessel, due to accelerated devitrification, which can largely be obviated by care in the cleansing of the vessel.

In general, fused silica is unattacked by metals and metallic vapours in a non-oxidising atmosphere, and it has, in fact, been used for the distillation of many pure metals in vacuo. The noble metals, as well as mercury, tin, zinc, cadmium, lead, and copper, are without action in such an atmosphere. Powerful reducing agents, such as aluminium above $800^{\circ} \mathrm{C}$, magnesium, cerium, and calcium, at a bright red heat, and sodium vapour, all attack silica by direct reduction. Oxides which form stable silicates are found to attack fused silica vessels upon ignition, but this does not preclude the use of silica crucibles, etc., for the ignition of granular precipitated oxides, provided these do not fuse, and thus do not wet the surface of the silica under the conditions of ignition.

Fused silica is permeable to gases at high temperatures. Helium begins to diffuse at $\mathrm{x} 80^{\circ} \mathrm{C}$., hydrogen at $300^{\circ} \mathrm{C}$, nitrogen at $600^{\circ} \mathrm{C}$. A well-evacuated bulb of one litre capacity and wall thickness $\mathrm{I} \cdot 5 \mathrm{~mm}$. may be heated in air at $400^{\circ} \mathrm{C}$. for roo hours before the internal pressure reaches $10^{-4} \mathrm{~mm}$., the gas which diffuses into the bulb being mainly nitrogen.

Fused silica has outstanding advantages as an

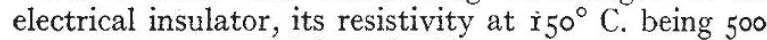
times that of porcelain. At higher temperatures the resistivity (in megohms per $\mathrm{cm} .{ }^{3} \rightarrow$ is, at $230^{\circ} \mathrm{C} .2 \times 10^{7}$, at $250^{\circ}$ C. $2.5 \times 10^{2}$, at $700^{\circ}$ C. $3 \times 10^{1}$, at $800^{\circ}$ C. $2 \times 10^{1}$. Fused silica is also less hygroscopic than glass and porcelain, and therefore less liable to produce surface leakage. Its specific inductive capacity is $3 \cdot 5-3 \cdot 6$, as compared with porcelain at $5 \cdot 6$. Its dielectric strength is equal to that of the best glass.

In optical properties fused silica is interesting for its high transparency to ultra-violet radiation, visible light, and heat. Fig. 6 shows an experiment in which a fused

$$
\text { NO. } 2847 \text {, VOL. I I } 3]
$$


silica rod $4 \mathrm{ft}$. long, and bent through $270^{\circ}$, has one end $\mid$ appreciable amount of heat is transmitted through heated to incandescence by an oxy-hydrogen blowpipe. $4 \mathrm{ft}$. of fused silica, and in working short lengths of rod

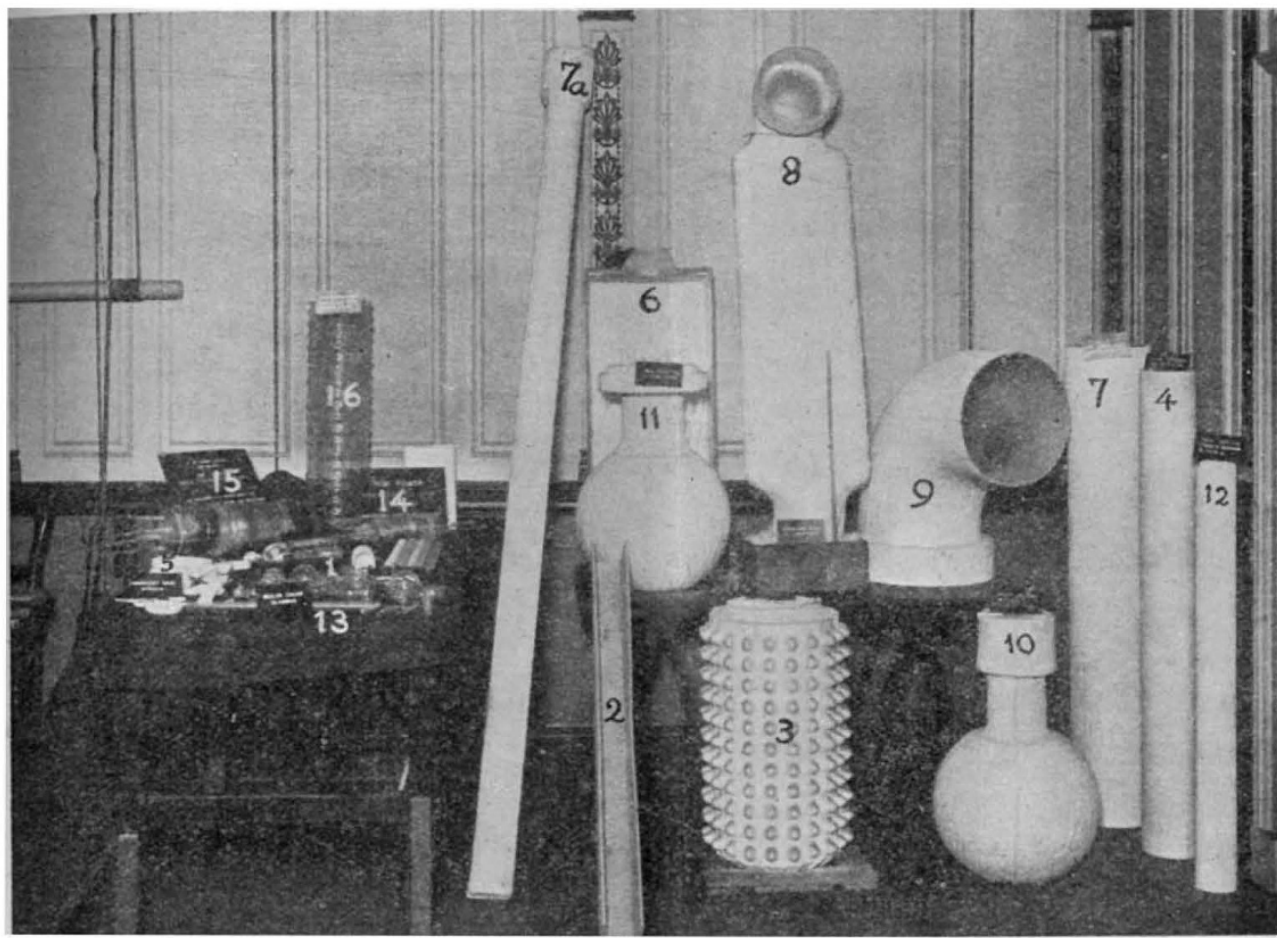

Fic. 4.-Photograph of exhibits (transparent and heavy chemical ware, etc.).

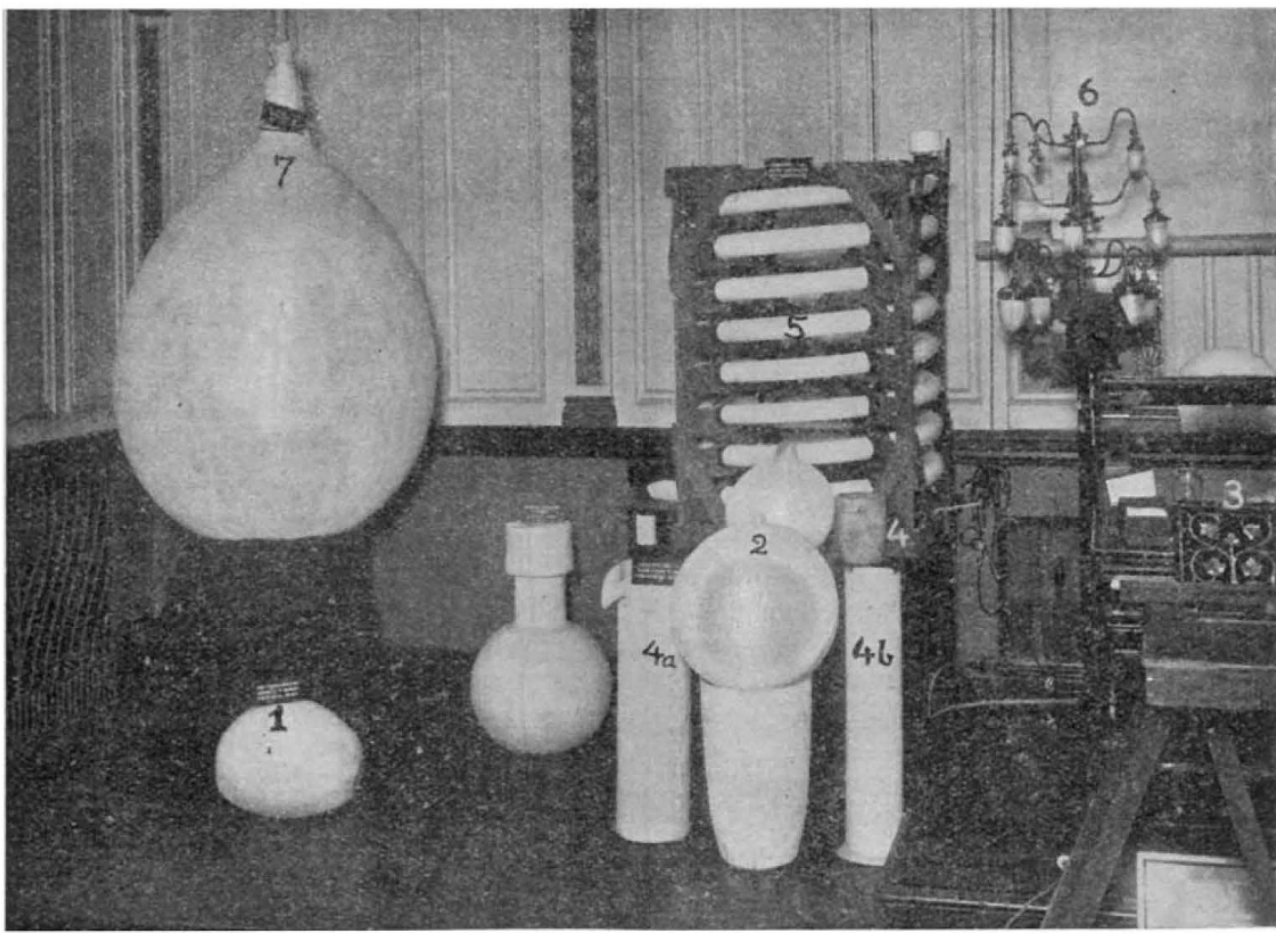

FIG. 5.-Photograph of exhibits ("Ostrich Egg," big flask, Brussels Exhibition fire exhibit, etc.).

The light passes through the length of the rod, being guided by internal reflection, and emerges at the thickened opposite end as a colourless beam. An with a blowpipe, the operator must take care not to burn his fingers with the radiant heat which emerges at the cold end of the rod.

NO. 2847 , VOL. I I 3$]$ 
Fused silica is quite transparent to ultra-violet rays down to $\lambda=0.226 \mu$ to $0.220 \mu$, and to some extent down to $\lambda=0.189 \mu\left(\mu=10^{-3} \mathrm{~mm}\right.$.). Thus, a screen of fused silica allows the passage of ultra-violet radiations, so as to discharge an electrically charged zinc plate, while the substitution of a glass screen prevents the discharge. Similarly, a solution of potassium iodide and starch

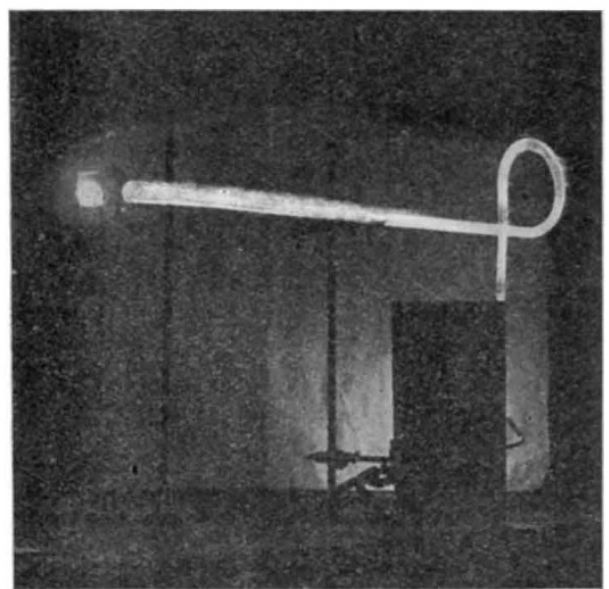

FIG. 6.-Transmission of light through silica rod.

contained in a fused quartz vessel is rapidly discoloured by the ultra-violet light from a mercury arc, while a similar solution in a glass vessel is unaffected, owing to the absorption of the active rays by the glass. This property of fused silica has found useful application in America in the sterilisation of water and other liquids by the action of ultra-violet light from mercury vapour lamps. The refractive index of fused silica ranges from $\mathrm{I} \cdot 456 \mathrm{I}$ for the lithium " $\mathrm{r}$ " line $(670.8 \mu \mu)$ to $\mathrm{I} \cdot 5743$ for the aluminium line at $\mathrm{r} 85 \cdot 2 \mu \mu$.

Apart from chemical uses, the most important commercial field for fused silica at the present time is in the manufacture of globes for incandescent gas burners (Fig. 5, No. 6). These, though considerably more expensive than glass, are entirely unaffected by heat changes, and also allow of a higher flame temperature (due to the reduction of excess of air round the flame), so as to produce an increased lighting efficiency. In the case of globes and laboratory ware, the material is glazed on both sides by a subsequent heat treatment. Fig. 4 (No. 3) shows the moulding of a cluster of small laboratory crucibles before the operations of cutting off and reheating.

Transparent fused silica envelopes are especially suitable for large thermionic valves for wireless telegraphy. Fig. 4 (Nos. ${ }_{4}$ and I $_{5}$ ) shows the Admiralty type of $5 \mathrm{kw}$. and Io $\mathrm{kw}$. valves respectively, the larger valve being due to Morris Airey, and manufactured by the Mullard Radio Valve Co. Messrs. Kelvin, Bottomley and Baird have successfully developed optical fused quartz for various purposes, and have specialised on silica mercury vapour lamps, and silica enveloped gas-filled lamps. The earliest fusion made by the Thermal Syndicate in 1904 is shown at Fig. 5 (No. I) ; their latest fusion, a flask of 170 gallons capacity, is shown at No. 7 of the same figure, and indicates the advance made during the first twenty years of the industry.

My thanks are due to Dr. Drane, Research Engineer to the Thermal Syndicate, for the experiments and many of the data described.

\section{The Mineral Resources of the British Empire.}

\section{By Thomas CROok.}

D URING recent years there has been much incentive to the study of natural resources of every description. The manifold and complex needs of industrial civilisation are such as to make it invidious to select any aspect of natural resources as being of more vital significance than the rest; but it requires only a little consideration to realise how very important to any country its reserves of mineral wealth must be. 'These reserves have been described very aptly as "wasting assets," in contrast with those yielded by the soil, which are reproductive. The quantities of minerals available are limited, and are so small as to justify the suspicion that in two or three generations from the present time it may be difficult, if at all possible, to obtain supplies of many important minerals at a rate sufficiently cheap to ensure industrial expansion, or even to maintain industries at their present level of prosperity. The importance of this prospective impoverishment of resources as regards base metals has been duly emphasised on various occasions recently by Sir Richard Redmayne, Sir Thomas Holland, and Prof. Thomas Turner.

Minerals, indeed, are fundamental requisites in the production of power and power machinery, on which the foundation of all industrial efficiency is based. Without an ample supply of coal, iron, and base metals, no country can travel far on the path of industrial progress, however efficient its human equipment may be. On the contrary, for any country adequately equipped with these primary needs of industrial development, there is scarcely any limit to trade expansion. In this connexion, and showing the value of outputs of fuels, iron ore, and base metals as indicators of commercial prosperity, it is noteworthy that the wealthiest and industrially the most prosperous country in the world at present (the United States) is the world's leading producer of coal, petroleum, iron ore, copper, aluminium, lead, and zinc. Moreover, the United States outputs of coal, petroleum, iron ore, and aluminium are consumed largely in its own productive industries; while without the base metal supplies of the United States, which are largely in excess of its own requirements, many another country would find its industries handicapped.

The world's industries, however, are still at the developing stage. The investigation and development of the resources of the United States are much more advanced than those of the British Empire. This is due in large measure not merely to the energy of the United States citizen, but also to the compactness of his country. The area of the United States is enormous, and the distribution of its resources is such as to present serious difficulties in the commercial cooperation of the western and eastern parts of the

$$
\text { No. } 2847 \text {, voL. I I } 3]
$$

